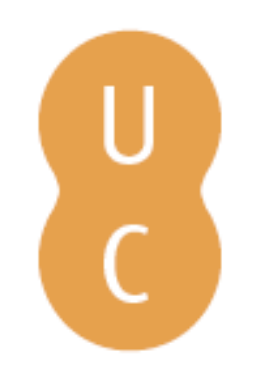

\title{
pombalina
}

\section{Relações entre a litologia e a ocupação e uso do solo na Região da Bairrada}

Autor(es): $\quad$ Almeida, João; Dinis, Pedro; Tavares, Alexandre

Publicado por: Imprensa da Universidade de Coimbra; Laboratório de Radioactividade

URL

persistente: URI:http://hdl.handle.net/10316.2/36292

DOI: $\quad$ DOI:http://dx.doi.org/10.14195/978-989-26-1009-2_5

Accessed : $\quad$ 26-Apr-2023 15:05:27

A navegação consulta e descarregamento dos títulos inseridos nas Bibliotecas Digitais UC Digitalis, UC Pombalina e UC Impactum, pressupõem a aceitação plena e sem reservas dos Termos e Condições de Uso destas Bibliotecas Digitais, disponíveis em https://digitalis.uc.pt/pt-pt/termos.

Conforme exposto nos referidos Termos e Condições de Uso, o descarregamento de títulos de acesso restrito requer uma licença válida de autorização devendo o utilizador aceder ao(s) documento(s) a partir de um endereço de IP da instituição detentora da supramencionada licença.

Ao utilizador é apenas permitido o descarregamento para uso pessoal, pelo que o emprego do(s) título(s) descarregado(s) para outro fim, designadamente comercial, carece de autorização do respetivo autor ou editor da obra.

Na medida em que todas as obras da UC Digitalis se encontram protegidas pelo Código do Direito de Autor e Direitos Conexos e demais legislação aplicável, toda a cópia, parcial ou total, deste documento, nos casos em que é legalmente admitida, deverá conter ou fazer-se acompanhar por este aviso.

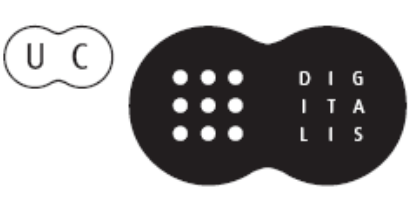




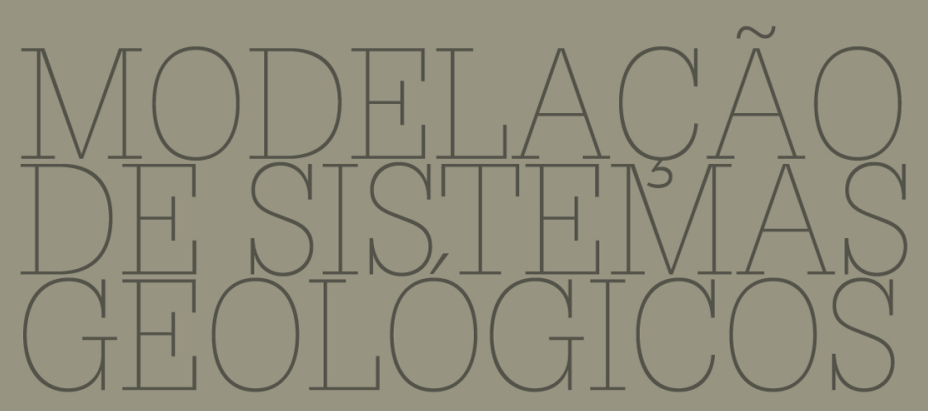

Homenagem ao Professor Doutor Manuel Maria Godinho

L.J.P.F. Neves, A.J.S.C. Pereira,

C.S.R. Gomes, L.C.G. Pereira,

A.O. TAVARES

IMPRENSA DA UNIVERSIDADE DE COIMBRA

CoImBra University Press 


\title{
MODELAÇÃO \\ DE SISTEMAS \\ GEOLÓGICOS
}

Homenagem ao Professor Manuel Maria Godinho

\section{Relações entre a litologia e a ocupação e uso do solo na Região da Bairrada}

\author{
João Almeida ${ }^{1}$; Pedro Dinis ${ }^{2}$; Alexandre Tavares ${ }^{3}$ \\ ${ }^{1}$ Universidade de Coimbra, Dep. de Ciências da Terra, PORTUGAL, jpedrodealmeida@gmail.com \\ 2Universidade de Coimbra, Dep. de Ciências da Terra, IMAR, PORTUGAL, pdinis@dct.uc.pt \\ ${ }^{3}$ Universidade de Coimbra, Dep. de Ciências da Terra, CES, PORTUGAL, atavares@ci.uc.pt
}

Palavras-chave: Região da Bairrada, Unidades líticas, Uso e ocupação do solo, Vinha

\section{Resumo}

No presente trabalho analisamos as relações espaciais entre a ocupação e uso do solo e a natureza lítica na Região da Bairrada (segundo a delimitação proposta para a área de produção vinícola, DOC-VQPRD). Esta análise permite diferenciar um domínio central e duas faixas, a oriente e ocidente, com maior afinidade com as regiões confins. No domínio central há uma clara simpatia das vinhas com unidades calco-margosas do Jurássico. Contudo, estas unidades líticas e de ocupação ocorrem numa área muito limitada não tipificando a região. Os "sistemas culturais parcelares complexos" (bairros), pela frequência e distribuição, parecem constituir a principal característica unificadora da região da Bairrada.

Key-words: Region of Bairrada, Lithic units, Land use, Vineyards

\begin{abstract}
In this work we analyse the spatial relationships between soil use and bedrock lithology in the region of Bairrada (defined following the limits proposed for the wine production region, DOC-VQPRD). This analysis reveals a central domain and two strips, to the west and east, with higher affinity with bordering regions. In the central domain there is a clear empathy between vineyards and Jurassic marl to calcareous units. However, these lithologic and soil use units are present in restricted areas. The "complex cultivation patterns" ("bairros"), by their frequency and distribution, seem to be the main unifying feature of region of Bairrada.
\end{abstract}

\section{Introdução}

$\mathrm{O}$ substrato lítico condiciona as características dos solos $\mathrm{e}$ as potencialidades dos terrenos para os vários tipos de ocupação, sendo o 
entendimento das relações entre a geologia e tipos específicos de ocupação do solo especialmente importante quando estão em causas produtos cujo valor (económico, cultural ou outro) se pretende valorizar. Nesse sentido, têm sido publicados diversos trabalhos sobre a geologia de regiões produtoras de vinhos de qualidade (Pomerol, 1985; Wilson, 1998; Munóz, 2009).

Os limites da região da Bairrada foram historicamente mutáveis. As sucessivas definições apresentam alguma semelhança com a sugerida no mapa de António Augusto de Aguiar (Paiz vinhateiro da Bairrada, de 1867), tendo como elemento diferenciador da Região a grande apetência vitivinícola e as características que lhe estão associadas (Mota, 1993). No Decreto-Lei N. ${ }^{\circ} 301 / 2003$, de 4 de Dezembro, Portaria N. ${ }^{\circ} 836 / 2004$, de 13 de Julho e Reg. (CE) 1493/99, de 17 de Maio, é apresentada a delimitação da região, que visa a produção de vinhos D.O.C.-V.P.Q.R.D. O território da Região Demarcada da Bairrada ocupa parte dos distritos de Aveiro e Coimbra, estendendo-se pelo todo ou parte dos concelhos de Anadia, Mealhada, Oliveira do Bairro, Águeda, Aveiro, Cantanhede, Coimbra e Vagos. É esta definição geográfica (Figura 1), por ser a mais recente e aquela que define a área de produção vitivinícola que se pretende valorizar, que suporta a análise agora apresentada.

No presente trabalho faz-se uma análise das relações (naturais ou antropogénicas) entre a natureza do suporte lítico e o tipo de ocupação do solo na região da Bairrada. Procede-se também a uma avaliação da distribuição espacial destas duas variáveis no seio da região.

\section{Metodologia}

A representação do substrato lítico da Região envolveu a integração e conciliação de diferentes fontes cartográficas, como a resultante da Carta Geológica de Portugal na escala 1/50.000 (Teixeira e Zbyszewski, 1976; Barbosa, 1981; Barbosa et al., 1988) e dos esboços geológicos da cidade de Coimbra (Soares et al., 1985), do concelho de Coimbra (Tavares, 1999), do vale do Cértima (Courbouleix, 1972; Dinis, 2004) e da Plataforma Litoral a norte do rio Águeda (Gomes, 2008), e novos levantamentos cartográficos. Procedeu-se a uma generalização da representação lítica de forma a obter unidades com homogeneidade composicional e estrutural capaz de condicionar a ocupação e uso dos solos, desvalorizando-se as informações cronostratigráficas. O mapa litológico assim criado foi georreferenciado e representado em suporte digital recorrendo-se ao software ArcGis 9.2 (ESRI®) e aparece representado na Figura 1. 


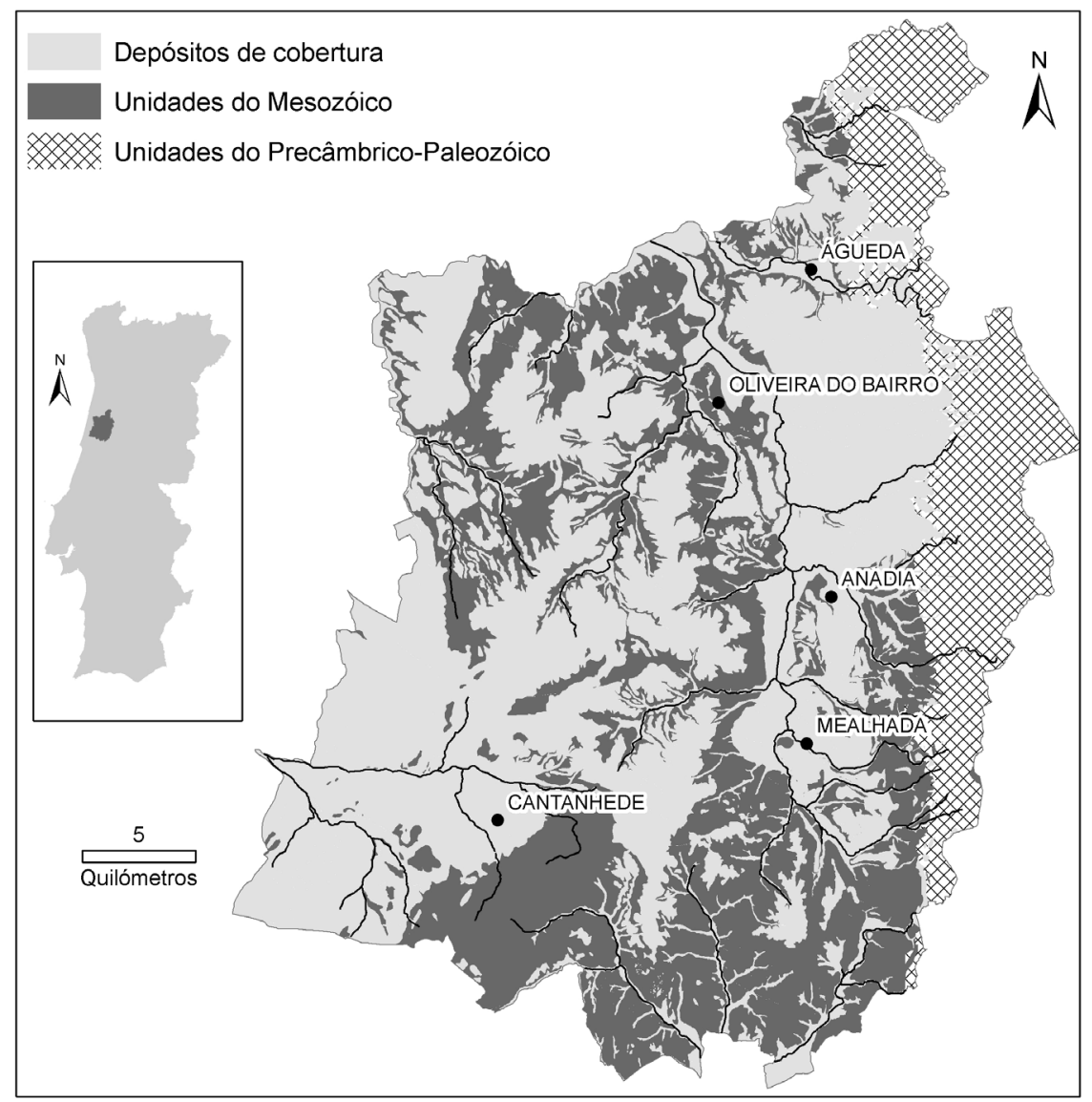

Figura 1. Localização da região da Bairrada no território português e distribuição dos grandes conjuntos líticos da Região.

A informação sobre a ocupação cultural da região baseou-se na classificação e representação de biótopos de CORINE (Corine, 2000; Caetano et al., 2009), tendo-se utilizado os vários níveis de classificação (níveis 1 e 2 e classes).

Para a análise das relações entre as unidades líticas e a ocupação do solo recorreu-se às ferramentas Analysis Tools e Spatial Analyst Tools do software ArcGis 9.2 (ESRI $\left.{ }^{\circledR}\right)$. A significância das relações foi determinada a partir de tabelas de contingência, com teste de $\chi 2$. 


\section{Natureza do substrato lítico}

A Região Demarcada da Bairrada apresenta, genericamente, como suporte litológico os terrenos da Orla Mesocenozóica e do Maciço Hercínico, materializados por rochas metamórficas pelíticas, rochas sedimentares carbonatadas e detríticas, com diferentes níveis de coesão, e uma cobertura de sedimentos friáveis. Num primeiro nível de análise, as unidades líticas foram agrupadas em "depósitos de cobertura", "unidades do Mesozóico" e "unidades do Precâmbrico-Paleozóico" (Tabela 1).

Nos depósitos de cobertura estão integrados os sedimentos de idade pliocénica a holocénica, friáveis, de disposição sub-horizontal, que, regra geral, constituem suportes líticos pouco espessos. Ficam neste grupo de unidades as aluviões, as areias eólicas, os depósitos de terraço, os sedimentos areno-cascalhentos litorais e os sedimentos argilo-cascalhentos continentais (Tabela 1, Figura 1). Estes sedimentos estão presentes em 55673,9 hectares, correspondendo a 54,7 \% da área total da Região.

As unidades do Mesozóico estão representadas por conjuntos dominantemente carbonatados e detríticos com diferentes estados de consolidação. Para uma melhor caracterização, o conjunto dos materiais do Mesozóico foi subdividido em cinco unidades líticas: argilosas do Cretácico; areno-carbonatadas do Cretácico; calcárias do Jurássico; calcomargosas e dolomíticas do Jurássico; e detríticas do Triásico-Jurássico (Tabela 1, Figura 1). Algumas das unidades consideradas apresentam grande variabilidade volumétrica dos termos líticos, mas preservando uma homogeneidade genética e de registo sedimentar que permite o cruzamento com outros níveis de informação. As unidades do Mesozóico têm uma representação superficial de 29.839,5 hectares, constituindo $32,1 \%$ da área total da Bairrada.

As unidades do Paleozóico e Precâmbrico posicionam-se na zona mais oriental da Bairrada, ocupando $13 \%$ da área da Região. Foram considerados quatro sub-conjuntos: "xistos" da Zona Centro Ibérica; "xistos" da Zona de Ossa Morena; filádios e quartzitos do Ordovícico-Sílurico (ZCI); unidades detríticas do Carbónico-Pérmico (Tabela 1, Figura 1).

Tabela 1. Unidades líticas definidas para a região da Bairrada

\begin{tabular}{|c|c|c|c|}
\hline & Unidades & $\begin{array}{c}\text { Unidades geológica julgadas } \\
\text { equivalentes }\end{array}$ & $\begin{array}{l}\text { Termos líticos } \\
\text { dominantes }\end{array}$ \\
\hline \multirow{3}{*}{ 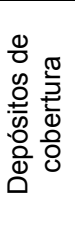 } & Aluvião & Aluvião & $\begin{array}{l}\text { Cascalhos, areias e } \\
\text { argilas }\end{array}$ \\
\hline & Areias eólicas & $\begin{array}{c}\text { Dunas holocénicas/Areias de Gândara } \\
\text { (Barbosa, 1981; Barbosa et al., 1988) }\end{array}$ & Areias bem calibradas \\
\hline & Depósitos de terraço & $\begin{array}{c}\text { Depósitos de terraços Q2b, Q3 e Q4 } \\
\text { (Barbosa, 1981; Teixeira e Zbyszewski, } \\
\text { 1976) }\end{array}$ & $\begin{array}{l}\text { Cascalhos, areias e } \\
\text { argilas }\end{array}$ \\
\hline
\end{tabular}


Tabela 1 (continuação)

\begin{tabular}{|c|c|c|c|}
\hline & Unidades & $\begin{array}{c}\text { Unidades geológica julgadas } \\
\text { equivalentes }\end{array}$ & $\begin{array}{l}\text { Termos líticos } \\
\text { dominantes }\end{array}$ \\
\hline \multirow{6}{*}{$\begin{array}{l}\frac{\pi}{2} \\
\frac{1}{0} \\
\frac{0}{0} \\
0 \\
\frac{0}{0} \\
0 \\
\frac{0}{10} \\
.0 \\
\frac{0}{0} \\
0\end{array}$} & \multirow{4}{*}{$\begin{array}{l}\text { Sedimentos areno- } \\
\text { cascalhentos litorais }\end{array}$} & $\begin{array}{c}\text { Depósitos de terraços Q1, Q2a e Q2b } \\
\text { (Barbosa, 1981; Teixeira e Zbyszewski, } \\
\text { 1976) }\end{array}$ & \multirow{4}{*}{$\begin{array}{l}\text { Areias finas cobertas } \\
\text { por areias grosseiras } \\
\text { com seixo; níveis } \\
\text { cascalhentos }\end{array}$} \\
\hline & & $\begin{array}{c}\text { Porção inferior da Formação de Aguada } \\
\text { (Grade \& Moura, 1980-81) }\end{array}$ & \\
\hline & & $\begin{array}{c}\text { Areias de Cordinhã, Cascalheiras de } \\
\text { Gordos e Areias de Cantanhede (Barbosa } \\
\text { et al., 1988) }\end{array}$ & \\
\hline & & U1 e U2A (Dinis, 2006) & \\
\hline & \multirow{2}{*}{$\begin{array}{l}\text { Sedimentos argilo- } \\
\text { cascalhentos } \\
\text { continentais }\end{array}$} & $\begin{array}{c}\text { Porção superior da Formação de Aguada } \\
\text { (Grade \& Moura, 1980-81) }\end{array}$ & \multirow[t]{2}{*}{$\begin{array}{l}\text { Alternância de argilas } \\
\text { e cascalhos e alguns } \\
\text { níveis de areias }\end{array}$} \\
\hline & & U2B e U3 (Dinis, 2006) & \\
\hline \multirow{13}{*}{ 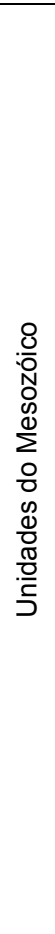 } & \multirow{4}{*}{$\begin{array}{l}\text { Unidades argilosas do } \\
\text { Cretácico }\end{array}$} & $\begin{array}{c}\text { Argilas da Pampilhosa (Marques et al., } \\
1974 \text { ) }\end{array}$ & \multirow{4}{*}{$\begin{array}{ll}\text { Argilitos com níveis } \\
\text { arenosos } \\
\text { intercalados; corpos } \\
\text { carbonatados } & \end{array}$} \\
\hline & & $\begin{array}{c}\text { Argilas de Aveiro (Teixeira \& Zbyszewski, } \\
1976)\end{array}$ & \\
\hline & & Argilas de Vagos (Barbosa, 1981) & \\
\hline & & Argilas de Viso (Barbc & \\
\hline & & $\begin{array}{c}\text { Arenitos de Mamodeiro (Teixeira e } \\
\text { Zbyszewski, 1976) }\end{array}$ & \multirow{4}{*}{$\begin{array}{l}\text { Comporta, do topo } \\
\text { para a base: } \\
-\quad \text { Arenitos } \\
\text { conglomerados com } \\
\text { argilas intercaladas; } \\
\text { - Calcários, margas, } \\
\text { grés calcários e } \\
\text { calcáris gresosos;- - } \\
-\quad \text { Arenitos e } \\
\text { conglomerados com } \\
\text { argilas intercaladas }\end{array}$} \\
\hline & & $\begin{array}{c}\text { Grés de Palhaça, Calcários de Mamarrosa, } \\
\text { Grés de Furadouro, Grés de Oiã, Grés de } \\
\text { Verba (Barbosa, 1981) }\end{array}$ & \\
\hline & & $\begin{array}{l}\text { Arenitos do Carrascal, Calcários de } \\
\text { Tentúgal, Grés de Furadouro, Grés de Oiã } \\
\text { (Barbosa et al., 1988) }\end{array}$ & \\
\hline & & Formação da Figueira da Foz (Dinis, 2001) & \\
\hline & $\begin{array}{c}\text { Unidades calcárias do } \\
\text { Jurássico }\end{array}$ & $\begin{array}{l}\text { Calcários de Ançã e Calcários de } \\
\text { Andorinha (Barbosa et al., 1988) }\end{array}$ & $\begin{array}{l}\text { Calcários micríticos, } \\
\text { cresosos e detríticos, } \\
\text { por vezes margosos }\end{array}$ \\
\hline & \multirow{2}{*}{$\begin{array}{l}\text { Unidades calco- } \\
\text { margosas e } \\
\text { dolomíticas do } \\
\text { Jurássico }\end{array}$} & $\begin{array}{l}\text { Camadas de Coimbra, Margas e Calcários } \\
\text { Margosos de Eiras e Margas e Calcários } \\
\text { Margosos de Pedrulha (Soares et al., 1985) }\end{array}$ & \multirow{2}{*}{$\begin{array}{l}\text { Calcários dolomíticos; } \\
\text { calcários margosos } \\
\text { ou micríticos com } \\
\text { alternâncias } \\
\text { margosas, mais ou } \\
\text { menos espessas }\end{array}$} \\
\hline & & $\begin{array}{l}\text { Formação de Vale das Fontes, F. Lemede, } \\
\text { F. S. Gião, Calcários de Póvoa da Lomba } \\
\text { (Duarte \& Soares, 2002) }\end{array}$ & \\
\hline & \multirow{2}{*}{$\begin{array}{l}\text { Unidades detríticas } \\
\text { do Triásico-Jurássico }\end{array}$} & Grés de Eirol (Teixeira \& Zbyszewsi, 1976) & \multirow{2}{*}{$\begin{array}{l}\text { Arenitos, conglomerados } \\
\text { e argilitos; niveis } \\
\text { margosos e dolomíticos }\end{array}$} \\
\hline & & Grés de Silves (Palain, 1976) & \\
\hline \multirow{4}{*}{ 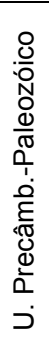 } & $\begin{array}{l}\text { Unidades detríticas } \\
\text { do Carbónico- } \\
\text { Pérmico }\end{array}$ & $\begin{array}{l}\text { Formação de Algeriz, F. Vale da Mó, F. } \\
\text { Monsarros (Domingos et al., 1983) }\end{array}$ & $\begin{array}{l}\text { Arenitos, } \\
\text { conglomerados } \\
\text { argilitos; níveis de } \\
\text { carvão }\end{array}$ \\
\hline & $\begin{array}{c}\text { Filádios e quartzitos } \\
\text { do Ordovícico-Silúrico }\end{array}$ & Ordovícico e Silúrico (Delgado, 1908) & Quartzitos e filitos \\
\hline & "Xistos" da ZCI & $\begin{array}{l}\text { Complexo Xisto-grauváquico (Medina, } \\
\text { 1996) }\end{array}$ & \begin{tabular}{|l|} 
Filitos \\
metagrauvaques
\end{tabular} \\
\hline & "Xistos" da ZOM & $\begin{array}{l}\text { Unidades de Arada, S. João de Ver e } \\
\text { Albergaria-a-Velha (Chaminé, 2000; } \\
\text { Chaminé et al., 2003) }\end{array}$ & $\begin{array}{l}\text { Filitos, micaxistos, } \\
\text { metagrauvaques, } \\
\text { xistos negros, e liditos }\end{array}$ \\
\hline
\end{tabular}




\section{Ocupação e uso do solo}

A ocupação cultural, definida a partir da cartografia Corine 2000, está organizada hierarquicamente em ocupação de nível 1, nível 2 e classes (Tabela 2). A região da Bairrada apresenta 19 classes distintas de ocupação do solo, definindo manchas cartográficas muito fragmentadas e com reduzida representação superficial ${ }^{1}$.

Os tipos de ocupação cultural de nível 1 com maior representação são as "florestas e meios semi-naturais" (49\%) e as "áreas agrícolas" (46\%). Os "territórios artificializados" representam apenas 5\% da Bairrada, enquanto as "zonas húmidas" e "massas de água" se limitam a percentagens residuais da região.

Tabela 2. Unidades de ocupação cultural para a região da Bairrada.

\begin{tabular}{|c|c|c|c|}
\hline Nível 1 & Nível 2 & Classe & $\begin{array}{l}\text { Área } \\
(\%)\end{array}$ \\
\hline \multirow{4}{*}{$\begin{array}{l}\text { Territórios } \\
\text { artificializados }\end{array}$} & Tecido urbano & Tecido urbano descontínuo & 3,1 \\
\hline & \multirow{2}{*}{$\begin{array}{l}\text { Indústria, comércio e } \\
\text { transportes }\end{array}$} & $\begin{array}{c}\text { Indústria, comércio e equipamentos } \\
\text { gerais }\end{array}$ & 1,4 \\
\hline & & $\begin{array}{c}\text { Redes viárias e ferroviárias e espaços } \\
\text { associados }\end{array}$ & 0,1 \\
\hline & $\begin{array}{l}\text { Áreas de construção, } \\
\text { extracção e depósitos de } \\
\text { resíduos }\end{array}$ & Áreas de extracção mineira & 0,4 \\
\hline \multirow{9}{*}{ Áreas agrícolas } & \multirow{3}{*}{ Culturas anuais } & Culturas anuais de sequeiro & 3,2 \\
\hline & & Culturas anuais de regadio & 1,6 \\
\hline & & Arrozais & 0,4 \\
\hline & \multirow{2}{*}{ Culturas permanentes } & Vinhas & 12,4 \\
\hline & & Olivais & 0,4 \\
\hline & Pastagens & Pastagens & 0,1 \\
\hline & \multirow{3}{*}{$\begin{array}{l}\text { Áreas agrícolas } \\
\text { heterogéneas }\end{array}$} & $\begin{array}{c}\text { Culturas anuais associadas às culturas } \\
\text { permanentes }\end{array}$ & 1,9 \\
\hline & & $\begin{array}{c}\text { Sistemas culturais e parcelares } \\
\text { complexos }\end{array}$ & 18,9 \\
\hline & & Agricultura com espaços naturais & 6,7 \\
\hline \multirow{4}{*}{$\begin{array}{l}\text { Florestas e meios } \\
\text { semi- } \\
\text {-naturais }\end{array}$} & \multirow{3}{*}{ Florestas } & Florestas de folhosas & 10,5 \\
\hline & & Florestas de resinosas & 18,1 \\
\hline & & Florestas mistas & 16,4 \\
\hline & $\begin{array}{c}\text { Vegetação arbustiva e } \\
\text { herbácea }\end{array}$ & $\begin{array}{c}\text { Espaços florestais degradados, cortes e } \\
\text { novas plantações }\end{array}$ & 4,0 \\
\hline
\end{tabular}

\footnotetext{
${ }^{1}$ Os mapas com a distribuição espacial dos vários níveis e classes de ocupação de uso podem ser observados em Almeida (2009).
} 
Tabela 2 (continuação)

\begin{tabular}{|c|c|c|c|}
\hline Nível 1 & Nível 2 & Classe & $\begin{array}{c}\text { Área } \\
\text { (\%) }\end{array}$ \\
\hline $\begin{array}{c}\text { Florestas e } \\
\text { meios semi- } \\
\text {-naturais }\end{array}$ & $\begin{array}{c}\text { Zonas descobertas e com pouca } \\
\text { vegetação }\end{array}$ & Vegetação esparsa & 0,0 \\
\hline \multirow{2}{\text{Zonas}}{ húmidas } & Zonas húmidas interiores & Pauis & 0,2 \\
\cline { 2 - 4 } & Zonas húmidas costeiras & Sapais & 0,0 \\
\hline $\begin{array}{c}\text { Massas de } \\
\text { água }\end{array}$ & Águas interiores & Planos de água & 0,2 \\
\cline { 2 - 4 } & Águas marinhas & Lagunas litorais & 0,0 \\
\hline
\end{tabular}

De entre as áreas classificadas como agrícolas, os "sistemas culturais e parcelares complexos" são a classe de ocupação mais frequente (19\%). Este tipo de ocupação representa uma estrutura complexa em que predomina o minifúndio, aparecendo distribuída de forma relativamente homogénea pela região, mas sobretudo nas proximidades dos agregados populacionais ou acompanhando o povoamento disperso ordenado ao longo das vias tradicionais de comunicação. As "vinhas", muitas vezes tidas como as culturas que caracterizam a Bairrada, ocupam apenas $12 \%$ da área total da Região, com representações muito reduzidas nos sectores orientais e ocidentais.

As florestas estão representadas pelas seguintes classes: "florestas de folhosas" (11\%), sobretudo na zona oriental; "florestas de resinosas" (18\%), sobretudo na zona sudoeste; e "florestas mistas" (16\%), mais comum na faixa de transição dos sectores mais elevados, a oriente, para o vale do rio Cértima ou, duma forma dispersa, a ocidente deste rio.

\section{Relações entre as unidades líticas e o uso do solo}

A análise da distribuição das unidades líticas e de ocupação e uso do solo sugere algumas tendências de associação. De facto, o teste de $\chi^{2}$ aplicado à tabela de contingência para as relações entre os tipos de substrato lítico e de ocupação do solo (Tabela 3) indica, para uma probabilidade de $95 \%$, que estas duas variáveis não são independentes $\left(\chi_{\text {obs. }}^{2}=106,1>\chi_{0,05 ;(13-1) \cdot(7-1)}^{2}=\right.$ 99,6).

Os resultados expressos na Figura 2 mostram que as "florestas de folhosas" são mais frequentes em materiais do Paleozóico e Precâmbrico e que as "florestas de resinosas" são dominante nas areias eólicas (Figura 2). Por seu lado, as "florestas mistas" são especialmente comuns nas unidades que sublinham a zona de contacto entre o Maciço Hercínico e a Orla Mesocenozóica Ocidental ("unidades detríticas do Triásico-Jurássico" e 
"sedimentos argilo-cascalhentos continentais", tidos como plioquaternários).

No que respeita às áreas agrícolas, a distribuição das vinhas merece particular atenção. Verifica-se que $42 \%$ das vinhas estão localizadas nas "unidades calco-margosas e dolomíticas do Jurássico" e que, 60\% das "unidades calco-margosas e dolomíticas do Jurássico" são ocupadas por vinhas (Figura 3). A relação das vinhas com as "unidades calco-margosas e dolomíticas do Jurássico" é comprovada pelo teste de $\chi^{2}$ aplicado a tabela de contingência de duas entradas em que se considera a presença ou ausência destes tipos litológicos e de ocupação de solos $\left(\chi_{\text {obs. }}^{2}=6,5>\chi_{0,05 ;(2-1) \cdot(2-1)}^{2}=\right.$ $3,8)$.

Tabela 3. Representação espacial das principais classes de uso e ocupação (com ocupação superior a 5\%) e das várias unidades líticas.

\begin{tabular}{|c|c|c|c|c|c|c|c|c|}
\hline $\begin{array}{c}\text { Ocupação e uso do solo } \\
\text { I Unidade lítica } \\
(\%)\end{array}$ & 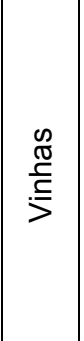 & 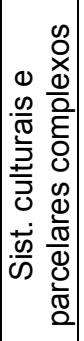 & 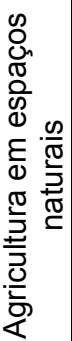 & 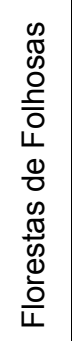 & 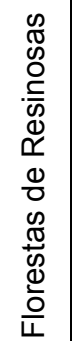 & 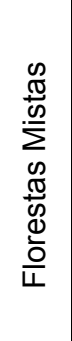 & $\begin{array}{l}\stackrel{0}{0} \\
\stackrel{0}{\frac{1}{5}} \\
\text { Oे }\end{array}$ & 要 \\
\hline Aluvião & 1,3 & 3,3 & 1,0 & 0,2 & 1,2 & 1,0 & 3,6 & 11,6 \\
\hline Areias eólicas & 0,2 & 0,6 & 0,8 & 0,0 & 5,5 & 0,4 & 1,3 & 8,7 \\
\hline Terraços & 0,2 & 1,5 & 0,2 & 0,0 & 0,3 & 0,6 & 0,8 & 3,6 \\
\hline Sedimentos areno-cascalhentos litorais & 3,3 & 6,4 & 1,1 & 0,3 & 4,8 & 4,2 & 5,0 & 25,1 \\
\hline Sedimentos argilo-cascalhentos continentais & 0,2 & 0,8 & 0,2 & 0,5 & 0,3 & 3,3 & 0,9 & 6,1 \\
\hline Unidades argilosas do Cretácico & 0,1 & 0,4 & 0,3 & 0,0 & 0,9 & 0,6 & 0,3 & 2,5 \\
\hline $\begin{array}{l}\text { Unidades gresosas e carbonatadas do } \\
\text { Cretácico }\end{array}$ & 1,6 & 2,3 & 1,6 & 0,0 & 4,2 & 2,5 & 1,8 & 14,1 \\
\hline Unidades Calcárias do Jurássico & 0,3 & 0,4 & 0,5 & 0,0 & 0,6 & 0,2 & 0,3 & 2,2 \\
\hline $\begin{array}{l}\text { Unidades Calco-margosas e dolomíticas do } \\
\text { Jurássico }\end{array}$ & 5,2 & 1,5 & 0,6 & 0,0 & 0,3 & 0,3 & 0,7 & 8,6 \\
\hline Unidades detríticas do Triásico-Jurássico & 0,1 & 1,2 & 0,3 & 0,3 & 0,0 & 2,0 & 0,5 & 4,4 \\
\hline Unidades detríticas do Carbónico-Pérmico & 0,0 & 0,1 & 0,0 & 1,8 & 0,0 & 0,3 & 0,0 & 2,2 \\
\hline Filádios e quartzitos do Ordovícico-Silúrico & 0,0 & 0,0 & 0,0 & 0,2 & 0,1 & 0,2 & 0,0 & 0,6 \\
\hline “Xistos” da Zona Centro Ibérica & 0,0 & 0,4 & 0,1 & 6,7 & 0,0 & 0,7 & 1,6 & 9,5 \\
\hline "Xistos" da Zona de Ossa Morena & 0,0 & 0,1 & 0,1 & 0,5 & 0,0 & 0,2 & 0,0 & 0,9 \\
\hline Total & 12,4 & 18,9 & 6,7 & 10,5 & 18,1 & 16,4 & 16,8 & 100 \\
\hline
\end{tabular}




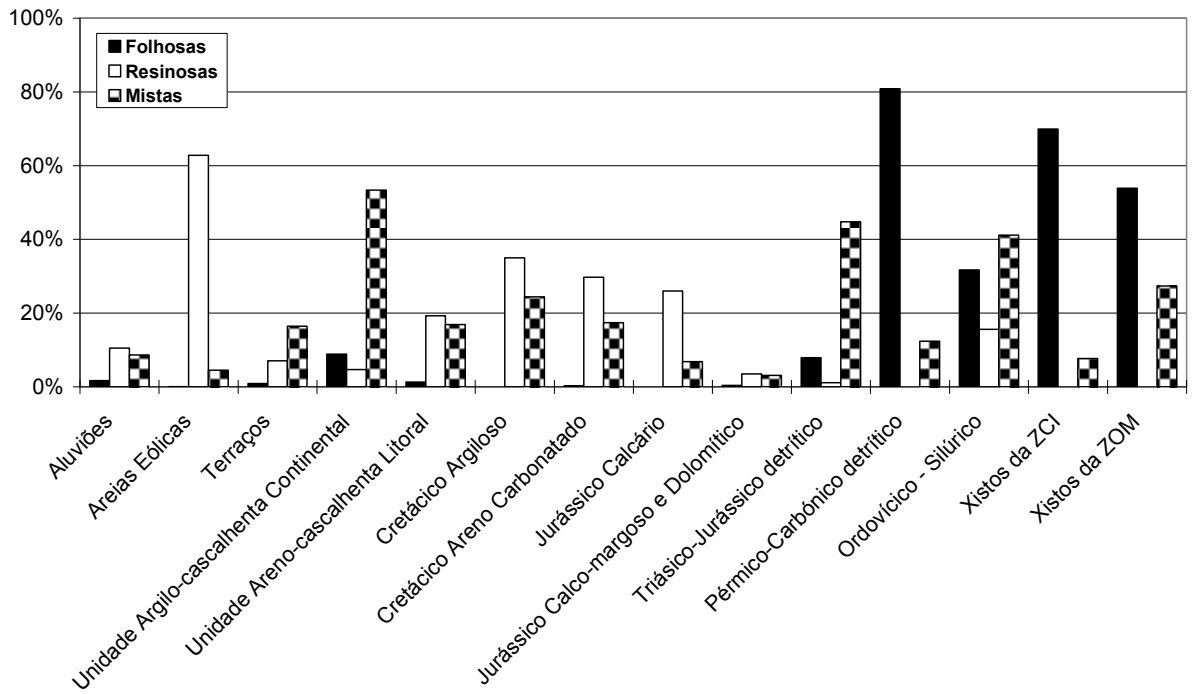

Figura 2. Percentagem de ocupação pelos diferentes tipos de floresta nas várias unidades líticas.

As distribuições desiguais das unidades líticas e de ocupação cultural leva-nos a considerar três sectores homogéneos:

- Faixa ocidental, de relevo pouco acentuado e suportada por areias eólicas, que apresenta uma ocupação dominada pelas "florestas de resinosas", revelando grande afinidade com a contígua região da Gândara.

- Faixa oriental, frequentemente com vertentes muito declivosas, em que se atingem as cotas mais elevadas, suportada por unidades do Paleozóico e Precâmbrico e onde domina a "floresta de folhosas";

- Zona central, ainda que com grande heterogeneidade lítica e de ocupação do solo, em que aparecem bem representados os usos agrícola (em especial os "sistemas culturais e parcelares complexos" e as "vinhas") e florestal (com domínio das "florestas mistas" nos sectores mais orientais e de "florestas de resinosas" nos sectores mais ocidentais).

Este último sector surge como o mais característico das actividades e paisagem que determinaram a individualização da região da Bairrada. 


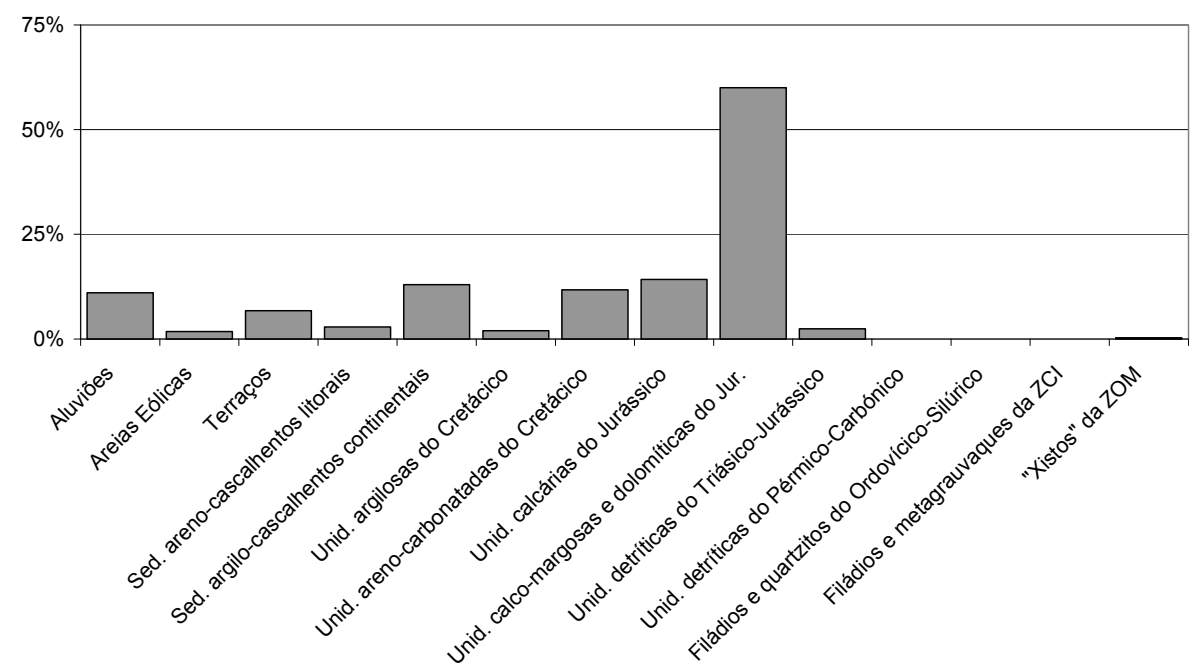

Figura 3. Percentagem de ocupação por vinhas nas diferentes unidades líticas.

A relação estabelecida entre a representação das unidades líticas e o uso e ocupação do solo permitem discutir ainda algumas das acepções da região da Bairrada. Assim, entender a região da Bairrada como uma área de "barros", tomando os limites da região DOC-VQPRD da Bairrada, revela-se de significado limitado dado que as unidades que poderiam promover solos argilosos, ricos em "barro", ocupam uma percentagem relativamente reduzida na Região ( $9 \%$ de "unidades calco-margosas e dolomíticas do Jurássico", 3\% de "unidades argilosas do Cretácico" e 6\% de "sedimentos argilo-cascalhentos continentais").

O entendimento da região da Bairrada como relacionada com a produção vitivinícola parece igualmente limitado, já que a ocupação por vinha é reduzida e está distribuída de forma muito heterogénea pela Região, apresentando grande simpatia com as "unidades calco-margosas e dolomíticas do Jurássico".

A região da Bairrada no sentido de "bairro rural, isto é, subúrbio extenso" ou "conjunto de bairros" (Rodrigues, 1959 in Silveira, 1994) mantêm alguma validade na sua zona central, que menos se confunde com as áreas confins a ocidente e oriente. De facto, os "sistemas culturais e parcelares complexos", muito associados à presença dos "bairros" e de espaços de interface urbano/rural, apresentam uma distribuição homogénea e pouco dependente do substrato lítico naquele sector central. Esta acepção, relacionada com uso e ocupação do solo, parece ainda hoje constituir um elemento unificador da região da Bairrada. 


\section{Conclusões}

As áreas mais orientais e ocidentais da Bairrada apresentam grande afinidade em termos de suporte lítico e de ocupação e uso do solo com as regiões confins. Se retirarmos estas zonas sobra-nos um sector central mais homogéneo, mas que ainda apresenta variabilidade significativa relativamente às características líticas e de uso e ocupação do solo. Contrariamente ao que muitas vezes é sugerido, a região da Bairrada, segundo a delimitação proposta para a área de produção vinícola (DOCVQPRD), não constitui "uma zona de barros" dado que as unidades líticas com estas características são pouco representativas.

Por sua vez, a cultura da vinha, surge distribuída de forma muito irregular, exibindo maior relação com as "unidades calco-margosas e dolomíticas do Jurássico".

A análise realizada salienta ainda que os "sistemas culturais e parcelares complexos", associados ao conceito de "bairros", são o tipo de ocupação mais comum e apresentam uma distribuição consistente na zona central da Bairrada, parecendo ser esta a principal característica unificadora da região.

\section{Bibliografia}

Almeida J. P. (2009) - Caracterização física da região da Bairrada: Contribuição para a valorização dos recursos endógenos. Dissertação de mestrado, Universidade de Coimbra, 99p.

Barbosa, B. P. (1981) - Notícia Explicativa da Folha 16-C (Vagos) da Carta geológica de Portugal na escala 1/50000. Serviços Geológicos de Portugal, 60p.

Barbosa, B. P., Soares. A. F., Rocha, R. B., Manuppela, G., Henriques, M. H. (1988) - Notícia Explicativa da Folha 19-A (Cantanhede) da Carta geológica de Portugal na escala 1/50000. Serviços Geológicos de Portugal.

Caetano, M., V. Nunes, A. Nunes. (2009) - CORINE Land Cover 2006 for Continental Portugal. Relatório técnico, Instituto Geográfico Português, 97p.

Chaminé, H. I. (2000) - Estratigrafia e estrutura da faixa metamórfica de Espinho-Albergaria-a-Velha (Zona de Ossa-Morena): implicações geodinâmicas. Tese de doutoramento, Universidade do Porto, $497 \mathrm{p}$.

Chaminé H. I., Gama Pereira L. C., Fonseca P. E., Moço L. P., Fernandes J. P., Rocha, F. T., Flores D., Pinto de Jesus A., Gomes C., Soares de Andrade A. A., Araújo, A. (2003) Tectonostratigraphy of Middle and Upper Palaeozoic black shales from the Porto-TomarFerreira do Alentejo shear zone (W Portugal): new perspectives on the Iberian Massif. Geobios, $n^{\circ} 36,649-663$.

Corine Land Cover (2000) - Disponível em: http//www.iambiente.pt. Consultado em Abril de 2008.

Courbouleix, S. (1972) - Etude geologique des regions de Anadia Mealhada, au Nord de Coimbra (Portugal). Mem. Faculte des Sciences, Universite Lyon, 342p.

Delgado, N. (1908) - Système silurique du Portugal. Etude de stratigraphie paléontologique. Mem. e Comunic. dos Serviços Geológicos de Portugal, 245p.

Dinis, J. L. (2001) - Definição da Formação da Figueira da Foz - Aptiano a Cenomaniano do sector central da margem oeste ibérica. Com. Inst. Geol. e Mineiro, Lisboa, 88, 127-160. 
Dinis, P. (2004) - Evolução pliocénica e quaternária do vale do Cértima. Dissertação de Doutoramento, Universidade de Coimbra, 351p.

Dinis, P. A. (2006) - Depósitos neogénicos anteriores à incisão fluvial actual entre Coimbra e Aveiro: fácies, arquitectura deposicional e controlos sobre a sedimentação, Comunicações Geológicas, 93, 81-104.

Domingos, L. C., Freire, J. L., Gomes da Silva, F., Gonçalves, F., Pereira, E., Ribeiro, A. (1983) The structure of intramontane upper carboniferous basins in Portugal. Actas The carboniferous of Portugal. M. J. Lemos de Sousa and J. T. Oliveira, (Eds.), Mem. Ser. Geol., Portugal, 187-194.

Duarte, L. V., Soares, A. F. (2002) - Litostratigrafia das séries margo-calcárias do Jurássico inferior da Bacia Lusitânica (Portugal). Com. Inst. Geol. e Mineiro, Lisboa; 89, 135-154.

Gomes, A. (2008) - Evolução Geomorfológica da Plataforma Litoral entre Espinho e Águeda. Dissertação de doutoramento, Universidade do Porto, 345p.

Grade, J., Moura, C. (1980-81) - Le basin sedimentaire d'Aguada-de-Cima (centre du Portugal). Bol. Soc. Geol. Portugal; 22, 197-260.

Medina, J. (1996) - Contribuição Para o Conhecimento da Geologia do Grupo das Beiras (CXG) na Região do Caramulo-Buçaco (Portugal). Dissertação de Doutoramento, Universidade de Aveiro, 200p.

Marques, L. F., Soares, A. F., Lima, L. S. (1974) - Contribuição para o estudo do Cretácico em Portugal (o Cretácico Superior de Marmeleira do Botão). Mem. Not. Publ. Mus. Lab. Min. Geol. Univ., Coimbra; 78, 105-133.

Mota, A. (1993) - Estudos regionais sobre a Bairrada. Figueirinhas, 114p

Munóz, A. (2009) - Geologia y Vinos de España. Ilustre Colegio Oficial de Geólogos, 540p.

Pomerol, C. (1985) - Terroirs et vins de France. Itinéraires Enologiques et Géologiques. Editions BRGM, 350p.

Palain, C. (1976) - Une série détritique terrigène. Les Grés de Silves: Trias et Lias inférieur du Portugal. Mem. Serv. Geol. Portugal; 25, 377p.

Soares, A. F.; Marques, J. F. \& Rocha, R. B. (1985) - Contribuição para o Conhecimento Geológico de Coimbra. Memórias e Notícias, Publ. Mus. Lab. Mineral. Geol. Univ. Coimbra, 100, 4371.

Tavares, A. M. O. S. (1999) - Condicionantes Físicas ao Planeamento. Análise da susceptibilidade no espaço do concelho de Coimbra, Dissertação de Doutoramento, Universidade de Coimbra. $346 \mathrm{p}$.

Teixeira, C., Zbyszewski, G. (1976) - Notícia Explicativa da Folha 16-A, Aveiro da Carta geológica de Portugal na escala 1/50000. Serviços Geológicos de Portugal.

Wilson, J. E. (1998) - Terroir: the role of geology climate and culture in the making of French wine. Mitchell Beazley, 1998, 336p. 